\title{
ELEVAÇÃO DAS VOGAIS MÉDIAS POSTÔNICAS NO SUL DO BRASIL: TENTATIVA DE GENERALIZAÇÃO DE RESULTADOS ${ }^{1}$
}

\author{
THE RAISING OF POST-TONIC MID VOWELS IN SOUTHERN BRAZIL: \\ AN ATTEMPT OF GENERALIZING RESULTS
}

Ivanete Mileski

Doutoranda do Programa de Pós-Graduação em Letras da Pontifícia Universidade Católica do Rio Grande do Sul ivanetemileski@gmail.com

RESUMO: Este estudo tem por objetivo analisar nove pesquisas variacionistas sobre elevação das vogais médias postônicas no Sul do Brasil, com vistas à generalização de resultados. Pautamo-nos, para tal, na proposta de Bailey e Tillery (2004), de acordo com a qual resultados distintos em estudos sobre um mesmo fenômeno podem refletir diferenças referentes à origem dos dados, à constituição da amostra e às estratégias analíticas adotadas. Levando em consideração esses três aspectos, foi possível encontrar resultados generalizáveis para a regra variável de elevação das vogais médias postônicas no Sul do Brasil.

PALAVRA-CHAVE:Variação Sociolinguística; Vogais Médias Postônicas; Generalização de Resultados.

ABSTRACT: This study aims to analyze nine variationist researches about the raising of posttonic mid vowels in Southern Brazil, in order to generalize results. We have considered the proposal of Bailey and Tillery (2004), according to which different results in studies of the same phenomenon may reflect differences concerning the origin of the data, the sample and the analytical strategies adopted. Taking these three aspects into account, we found generalizable results to the variable rule of the raising of post-tonic mid vowels in Southern Brazil.

KEYWORDS: Sociolinguistic Variation; Post-tonic Mid Vowels; Generalization of Results.

\section{INTRODUÇÃO}

Data de 1987 o primeiro estudo variacionista sobre a regra variável de elevação das vogais médias postônicas no Sul do Brasil, a exemplo de ['karo] ['karu], ['mole] ['moli], ['fosforo] ['fosfuro],[e'pẽteze] [e'pẽtize]. Trata-se da pesquisa de Schmitt (1987). Outros se seguiram analisando ora ambas as posições - postônica final e não final - (SCHMITT, 1987; VIEIRA, 1994, 2002, 2010; MACHRY DA SILVA, 2009), ora apenas a posição final (ROVEDA, 1998; CARNIATO, 2000; MALLMANN, 2001; MILESKI, 2013).

Neste artigo retomaremos tais estudos variacionistas referentes à elevação das vogais médias postônicas no Sul do Brasil com vistas à generalização de resultados, seguindo a metodologia proposta por Bailey e Tillery (2004). De acordo com esses autores, resultados divergentes em estudos sobre um mesmo fenômeno podem refletir diferenças relacionadas à origem dos dados, à constituição da amostra e às estratégias de análise adotadas. Assim, esses três aspectos serão considerados na comparação dos resultados, a fim de que possam ser

\footnotetext{
${ }^{1}$ Este artigo é uma adaptação da análise apresentada em Mileski (2013, p. 125-142).
} 
alcançadas generalizações quanto ao fenômeno de elevação das vogais médias postônicas no Sul do Brasil. Trata-se, portanto, de um exercício de análise de cada estudo em busca de melhor entendimento sobre resultados comuns e esclarecimentos referentes às estratégias metodológicas adotadas. Primeiramente analisamos comparativamente esses estudos para, então, apresentar uma síntese dos resultados que podem ser generalizados.

\section{ANÁLISE COMPARATIVA}

São em número de nove as pesquisas sobre elevação das vogais médias postônicas no Sul do Brasil a serem analisadas neste estudo, expostas no Quadro 1. Como é possível verificar na terceira coluna do quadro, adotamos uma denominação sintética para cada estudo, de acordo com a ordem cronológica de publicação.

Quadro 1Pesquisas consideradas neste estudo

\begin{tabular}{|c|c|c|}
\hline Autor & Ano & Denominação dada neste trabalho \\
\hline Schmitt & 1987 & P1 \\
\hline Vieira & 1994 & P2 \\
\hline Roveda & 1998 & P3 \\
\hline Carniato & 2000 & P4 \\
\hline Mallmann & 2001 & P5 \\
\hline Vieira & 2002 & P6 \\
\hline Machry da Silva & 2009 & P7 \\
\hline Vieira & 2010 & P8 \\
\hline Mileski & 2013 & P9 \\
\hline
\end{tabular}

Fonte: Autor

Considerando-se a origem dos dados, podemos afirmar, em concordância com Brescancini $(2008)^{2}$, que P1 (SCHMITT, 1987) e P2 (VIEIRA, 1994) são trabalhos diretamente comparáveis, pois ambos utilizam dados provenientes de uma coleta realizada por Bisol (1977-1978).

Como explicitado no Quadro 2, todos os informantes que compõem as amostras analisadas nesses dois trabalhos têm formação escolar primária incompleta e idade entre 25 e 55 anos. Os estudos diferenciam-se, no entanto, no que se refere à quantidade de informantes considerados: P1 analisa dados de quatro informantes de cada região (quatro bilíngues de Veranópolis - colonização italiana, quatro bilíngues de Taquara - colonização alemã, quatro monolíngues de Livramento - fronteira com o Uruguai); P2 analisa dados de sete informantes de cada uma dessas regiões e considera também outros sete monolíngues da região metropolitana de Porto Alegre. Em P1, foi realizada como teste a análise dos dados de apenas um informante da região metropolitana, confirmando-se a hipótese de que a aplicação da regra de elevação é praticamente categórica nessa região (constatou-se 97\% de aplicação para /o/ e $90 \%$ para /e/).

Quadro 2 Características das amostras de P1 e P2

${ }^{2}$ Brescancini (2008) analisa os trabalhos de Schmitt (1987), Vieira (1994, 2002), Roveda (1998) e Carniato (2000), pautada nos pressupostos de Bailey e Tillery (2004), na busca por resultados generalizáveis. 


\begin{tabular}{|c|c|c|c|c|c|c|}
\hline $\begin{array}{c}\text { Autor/ } \\
\text { Ano }\end{array}$ & $\begin{array}{c}\text { Cidades/ } \\
\text { informantes }\end{array}$ & $\begin{array}{c}\text { Total de } \\
\text { informantes e } \\
\text { de dados }\end{array}$ & $\begin{array}{c}\text { Faixa } \\
\text { etária }\end{array}$ & Escolaridade & Sexo & $\begin{array}{c}\text { Grupo } \\
\text { geográfico }\end{array}$ \\
\hline $\begin{array}{c}\text { P1 } \\
\text { Schmitt } \\
(1987)\end{array}$ & $\begin{array}{c}\text { Veranópolis }-4 \\
\text { Taquara }-4 \\
\text { Livramento }-4\end{array}$ & $\begin{array}{c}12 \text { inf. } \\
/ \mathrm{e} / 4.402 \\
/ \mathrm{o} / 7.280\end{array}$ & $\begin{array}{c}25-55 \\
\text { anos }\end{array}$ & $\begin{array}{c}\text { Primário } \\
\text { incompleto }\end{array}$ & $\begin{array}{c}\text { masculino } \\
\text { feminino }\end{array}$ & $\begin{array}{c}\text { alemães } \\
\text { italianos } \\
\text { fronteiriços }\end{array}$ \\
\hline P2 & $\begin{array}{c}\text { Veranópolis }-7 \\
\text { Taquara - } 7\end{array}$ & $\begin{array}{c}28 \text { inf. } \\
/ \mathrm{e} / 5.487 \\
\text { Vieira }\end{array}$ & $\begin{array}{c}25-55 \\
\text { anos }\end{array}$ & $\begin{array}{c}\text { Primário } \\
\text { incompleto }\end{array}$ & $\begin{array}{c}\text { masculino } \\
\text { feminino }\end{array}$ & $\begin{array}{c}\text { alemães } \\
\text { italianos } \\
\text { fronteiriços } \\
\text { metropolitanos }\end{array}$ \\
\hline
\end{tabular}

Fonte: Autor

As duas amostras diferenciam-se no que se refere ao número de informantes, no entanto, apesar de o total de informantes de $\mathrm{P} 2$ representar mais do dobro do total de informantes de P1, o número total de dados não difere nessa proporção: para /e/ são 4.402 dados em P1 e 5.487 em P2, e para /o/, 7.280 em P1 e 7.131 em P2. Vieira (1994) informa que foram selecionadas ocorrências cuja vogal produzida pôde ser ouvida com clareza, ou seja, foram descartados dados que tiveram interferências referentes à qualidade da gravação ou a outros sons do local; essa característica da seleção das ocorrências possivelmente esteja relacionada à quantidade de dados semelhante entre $\mathrm{P} 1$ e $\mathrm{P} 2$, apesar da diferença no número de informantes.

Os dois estudos consideram conjuntamente dados de vogal média postônica final e não final, analisando distintamente cada vogal, ou seja, um arquivo para /e/ final e não final, e outro arquivo para /o/ em ambas as posições.

Como se pode ver no Quadro 3, P1 e P2 diferenciam-se no que se refere às variáveis independentes controladas.

Quadro 3 Variáveis independentes linguísticas controladas em P1 e P2

\begin{tabular}{|l|c|c|c|c|c|c|c|c|c|}
\hline Acento & $\begin{array}{c}\text { Cont. } \\
\text { Prec. }\end{array}$ & $\begin{array}{c}\text { Cont. } \\
\text { Seg. }\end{array}$ & Juntura & $\begin{array}{c}\text { Classe } \\
\text { Morf. }\end{array}$ & $\begin{array}{c}\text { Posição } \\
\text { no Sint. } \\
\text { Frasal }\end{array}$ & $\begin{array}{c}\text { Cont. } \\
\text { Vocálico }\end{array}$ & $\begin{array}{c}\text { Tipo de } \\
\text { Sílaba }\end{array}$ & $\begin{array}{c}\text { Posição } \\
\text { na Sílaba }\end{array}$ \\
\hline P1 & & & & & & & & & \\
\hline P2 & & & & & & & & & \\
\hline
\end{tabular}

Fonte: Autor

Com relação às variáveis extralinguísticas consideradas, P1 e P2 controlam em comum a variável Tipo de Entrevista (teste ou fala livre). P2 analisa também Sexo e Etnia.

A seleção das variáveis não foi igual para P1 e P2. Das variáveis comuns controladas, não foram significativas para P2 Contexto Seguinte e Classe Morfossintática, que tiveram papel em P1. Também mostraram papel em P1 as variáveis Juntura, Contexto Precedente e Posição no Sintagma Frasal. Em P2, por ordem de relevância, tiveram papel: Etnia, Contexto Vocálico, Segmento Precedente, Tipo de Sílaba, Sexo e Posição na Sílaba. Assim, a única variável comum selecionada em ambas as pesquisas é Contexto Precedente.

Em se tratando de variáveis extralinguísticas, em ambas as amostras, a variável Etnia condiciona a aplicação da regra: em P1 isso se verifica pelas diferenças de aplicação da regra de acordo com o grupo geográfico, e em P2 Etnia foi a variável apontada como a de maior relevância para o alçamento de /o/. No Gráfico 1, observa-se a frequência de aplicação da regra para a vogal /o/ em P1 e P2, e no Gráfico 2, a frequência para a vogal /e/. 
Gráfico 1 Elevação da vogal /o/ em P1 e P2

Fonte: Autor

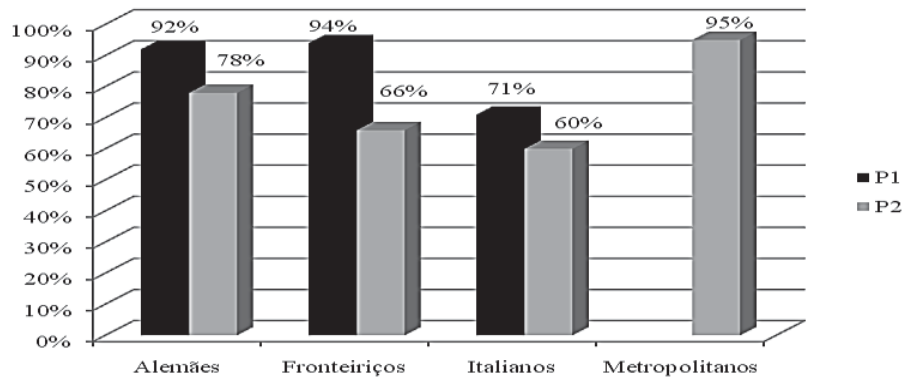

A partir do Gráfico 1 é possível observar que os informantes da região de colonização italiana são os que mais preservam /o/ postônico. Alemães e fronteiriços apresentam resultados bastante semelhantes em P1 (92\% e 94\%, respectivamente), e nos resultados de P2 fronteiriços apresentam comportamento mais próximo aos da região de colonização italiana (66\%), seja comparativamente a P1 (71\%) seja a P2 (60\%). O resultado de P2 para a região metropolitana confirma a análise efetuada para teste em P1.

Os resultados para a vogal /e/ apontam os informantes da região de colonização italiana novamente como os mais preservadores da vogal média, como mostra o Gráfico 2.

Gráfico 2 Elevação da vogal /e/ em P1 e P2

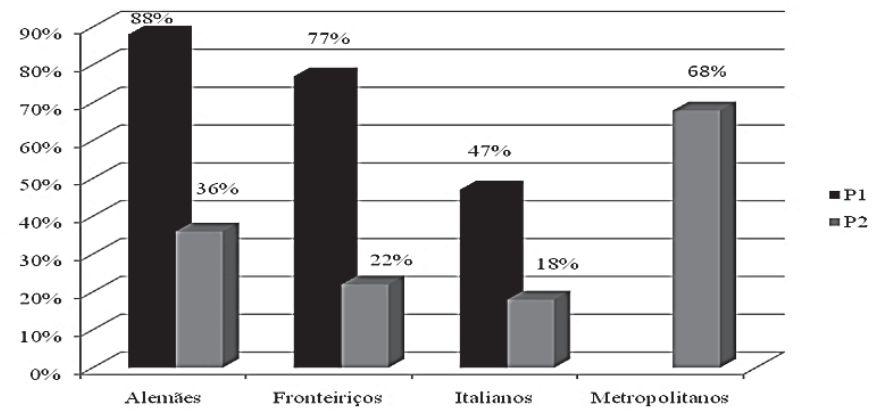

Fonte: Autor

Com relação à vogal /e/, em $\mathrm{P} 1$ os italianos apresentam taxa de aplicação da regra consideravelmente menor (47\%) se comparados a fronteiriços $(77 \%)$ e alemães $(88 \%)$, que não se diferenciam tanto. Já em P2 há maior semelhança entre italianos (18\%) e fronteiriços $(22 \%)$.

No que se refere a condicionamentos linguísticos, a variável Contexto Precedente foi selecionada em ambas as pesquisas, no entanto, diferenças na constituição dos fatores da variável dificultam generalizações. P1 organiza os fatores dessa variável de acordo com o ponto de articulação e separa o tepe das demais sonorantes, ao passo que P2 apresenta resultados com a distinção entre os segmentos /s, z/, nasais e líquidas, e os demais segmentos ficam agrupados sob o fator outros.

Para a vogal /o/, como se pode ver no Gráfico 3, P1 indica consoantes labiais como favorecedoras para os informantes de Taquara $(0,61)$; P2 agrupa esses segmentos sob o fator outros, o que mais favorece a aplicação da regra. Nos resultados de P2, segmentos /s, z/ são claramente inibidores de elevação de /o/, ao passo que em P1, juntamente com as oclusivas alveolares, mostram comportamento neutro para os três grupos étnicos. Em P1, nasais e a 
líquida lateral, agrupadas como outras sonorantes, mostram comportamento favorecedor para fronteiriços, no entanto, em P2 a líquida apresenta-se com um comportamento neutro.

Gráfico 3 Resultados para Contexto Precedente em P1 e P2: vogal /o/

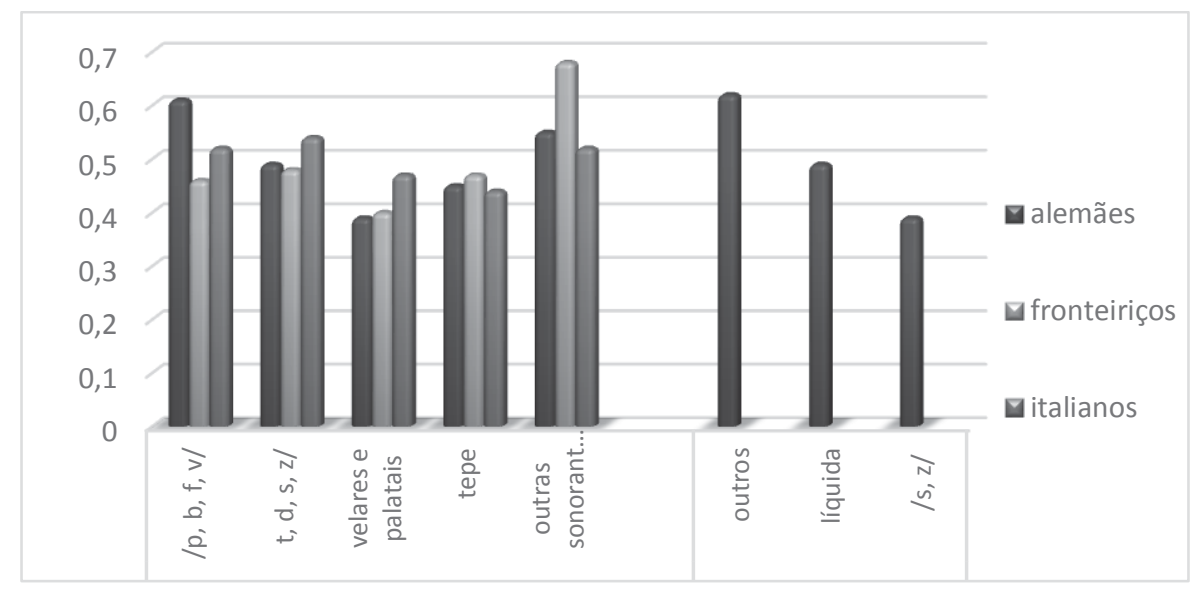

Fonte: Autor

Como se pode notar, não é possível alcançar nenhuma generalização referente ao papel do contexto precedente para a vogal /o/. O papel favorecedor das labiais no grupo dos alemães em P1 e o fato de tais segmentos estarem agrupados sob o fator que mais favorece a elevação em P2 permite supor que tais segmentos exercem papel favorável em ambas as pesquisas; são resultados que se aproximam, embora não generalizáveis, uma vez que labiais têm papel em P1 apenas para o grupo de alemães.

Com relação à vogal /e/, há resultados concordantes entre as duas pesquisas no que se refere ao favorecimento da elevação: os resultados de P1 indicam o papel favorável das velares e palatais, agrupadas no fator outros em $\mathrm{P} 2^{3}$, o que mais favorece a aplicação da regra, como se pode observar no Gráfico 4. Por outro lado, em P2, a líquida e as nasais mostram comportamento diferenciado - aquela é altamente inibidora, estas, favorecedoras, ao passo que, em P1, agrupadas sob o mesmo fator, mostram-se inibidoras para alemães e próximas ao ponto neutro para italianos e fronteiriços.

\footnotetext{
${ }^{3}$ Embora não seja possível analisar em separado o comportamento de consoantes dorsais em P2, acreditamos que isso não invalida a generalização, uma vez que em pesquisa sociolinguística apenas são amalgamados fatores cujo comportamento é similar.
} 
Gráfico 4 Resultados para Contexto Precedente em P1 e P2: vogal/e/

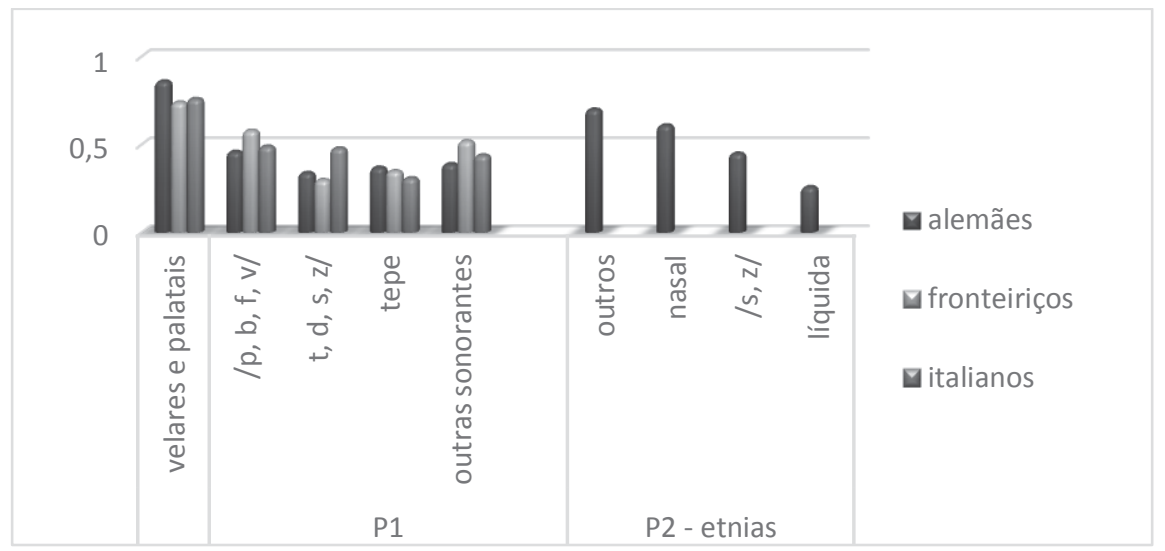

Fonte: Autor

Analisados os dois primeiros estudos, é possível verificar que, dos condicionamentos linguísticos encontrados para a regra de elevação das vogais médias postônicas em P1 e P2, o resultado em comum refere-se ao papel favorável das velares e palatais em contexto precedente para a elevação de /e/. Além disso, vê-se que o fator região geográfica ou etnia é relevante por permitir afirmar que existem dois sistemas vocálicos em pauta postônica no Rio Grande do Sul: um que tende a produzir as vogais altas /i, u/ no lugar das médias, e outro que preserva as vogais médias /e, o/.

Iniciaremos aqui a análise de outras três pesquisas. Considerando-se a fonte dos dados, podese dizer que P3 (ROVEDA, 1998), P6 (VIEIRA, 2002) e P8 (VIEIRA, 2010) são trabalhos que podem ser comparados, uma vez que os três utilizam dados do banco VARSUL (Variação Linguística na Região Sul do Brasil), coletados de 1988 a 1996. P3 considera dados de 48 informantes do Rio Grande do Sul e Santa Catarina: 12 monolíngues de cada uma das capitais - Porto Alegre e Florianópolis - e 12 bilíngues de cada uma das cidades de colonização italiana - Flores da Cunha (RS) e Chapecó (SC). P6 analisa dados de 96 informantes - oito informantes de cada uma das cidades contempladas pelo VARSUL (Porto Alegre, Flores da Cunha, Panambi e São Borja, no Rio Grande do Sul; Florianópolis, Blumenau, Lages e Chapecó, em Santa Catarina; Curitiba, Londrina, Pato Branco e Irati, no Paraná). P8 analisa dados de 48 informantes - 16 de cada uma das capitais: Porto Alegre, Florianópolis e Curitiba.

Como se pode observar no Quadro 4, P3 e P6 estratificam sua amostra de acordo com faixa etária e escolaridade, P3 considera também a variável sexo, enquanto P8 não inclui nenhuma variável social. A variável Faixa Etária possui praticamente a mesma segmentação em P3 e P6. Escolaridade é composta por três fatores em P3 e por dois fatores em P6.

Quadro 4 Características das amostras de P3, P6 e P8

\begin{tabular}{|c|c|c|c|c|c|c|}
\hline $\begin{array}{c}\text { Autor/ } \\
\text { ano }\end{array}$ & $\begin{array}{c}\text { Cidades/ } \\
\text { informantes }\end{array}$ & $\begin{array}{c}\text { Total de } \\
\text { informantes } \\
\text { e de dados }\end{array}$ & $\begin{array}{c}\text { Faixa } \\
\text { etária }\end{array}$ & Escolaridade & Sexo & $\begin{array}{c}\text { Grupo } \\
\text { geográfico }\end{array}$ \\
\hline $\begin{array}{c}\text { P3 } \\
\text { Roveda } \\
(1998)\end{array}$ & $\begin{array}{c}\text { Porto Alegre }-12 \\
\text { Flores da Cunha }-12\end{array}$ & $\begin{array}{c}48 \text { inf. } \\
/ \mathrm{o} / 9.369 \\
/ \mathrm{e} / 4.523\end{array}$ & $\begin{array}{c}25-50 \\
\text { Florianópolis }-12 \\
\text { Chapecó }-12\end{array}$ & $\begin{array}{c}\text { Até } 4 \text { anos } \\
4-8 \text { anos } \\
9-12 \text { anos }\end{array}$ & $\begin{array}{c}\text { masculino } \\
\text { feminino }\end{array}$ & $\begin{array}{c}\text { italianos } \\
\text { açorianos }\end{array}$ \\
\hline
\end{tabular}




\begin{tabular}{|c|c|c|c|c|c|c|}
\hline $\begin{array}{c}\text { P6 } \\
\text { Vieira } \\
\text { (2002) }\end{array}$ & $\begin{array}{c}\text { Porto Alegre }-8 \\
\text { Flores da Cunha }-8 \\
\text { São Borja }-8 \\
\text { Panambi }-8 \\
\text { Florianópolis }-8 \\
\text { Chapecó }-8 \\
\text { Lages }-8 \\
\text { Chapecó }-8 \\
\text { Curitiba }-8 \\
\text { Londrina }-8 \\
\text { Pato Branco }-8 \\
\text { Irati }-8\end{array}$ & $\begin{array}{c}96 \text { inf. } \\
\text { não final: } \\
\text { /o/ } 535 \\
\text { /e/ } 265 \\
\text { final: } \\
\text { /o/ } 768 \\
\text { /e/ } 876\end{array}$ & $\begin{array}{l}\text { Até } 50 \\
+ \text { de } 51\end{array}$ & $\begin{array}{l}\text { Até } 4 \text { anos } \\
+ \text { de } 4 \text { anos }\end{array}$ & - & $\begin{array}{c}\text { alemães } \\
\text { italianos } \\
\text { fronteiriços } \\
\text { açorianos } \\
\text { eslavos }\end{array}$ \\
\hline $\begin{array}{c}\text { P8 } \\
\text { Vieira } \\
(2010)\end{array}$ & $\begin{array}{c}\text { Porto Alegre }-16 \\
\text { Florianópolis - } 16 \\
\text { Curitiba }-16\end{array}$ & $\begin{array}{c}48 \text { inf. } \\
\text { não final: } \\
\text { /o/ } 144 \\
\text { /e/ } 136 \\
\text { final: } \\
\text { /o/ } 7.622 \\
\text { /e/ } 5.962\end{array}$ & - & - & - & - \\
\hline
\end{tabular}

Fonte: Autor

Como se verificana terceira coluna do Quadro 4, diferentemente de P1 e P2, em que vogais médias átonas finais e não finais foram tratadas conjuntamente, em P6 e P8 são analisadas em arquivos distintos; P3 atém-se à posição final. Dessa forma, serão comparados os resultados para a posição final das três pesquisas, ao passo que para a posição não final serão comparados os de P6 e P8.

No que se refere à frequência de aplicação para a posição final, podem-se comparar três resultados: os das três pesquisas para Porto Alegre e Florianópolis; os de P3 e P6 para Flores da Cunha e Chapecó; e os de P6 e P8 para Curitiba.

Como mostra o Gráfico 5, a frequência de aplicação em P3 e P8 para a posição final é bastante semelhante. P6 não apresenta distribuição por cidade para a vogal posterior, e a frequência para /e/ é mais baixa se comparada a P3 e P8. Essa diferença pode estar relacionada à diferença em número de dados entre $\mathrm{P} 6 \mathrm{e}$ as outras duas pesquisas.

Gráfico 5 Resultados para Florianópolis e Porto Alegre: vogais finais

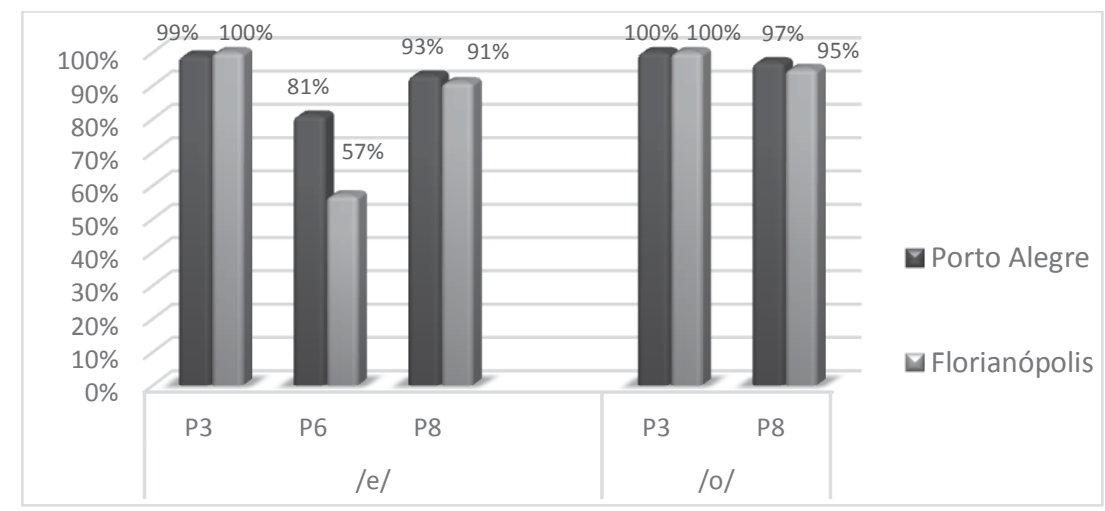

Fonte: Autor 
A frequência em P3 e P8 mostra a aplicação praticamente categórica da elevação para ambas as vogais tanto em Porto Alegre quanto em Florianópolis.

Comparando-se os resultados de frequência obtidos em P3 e P6 para Flores da Cunha e Chapecó, a menor quantidade de dados em P6 parece responsável também pela diferença no percentual de aplicação para /e/ entre seus resultados e os de P3, como mostra o Gráfico 6.

Gráfico 6 Resultados de P3 e P6 para Flores da Cunha e Chapecó: vogal/e/

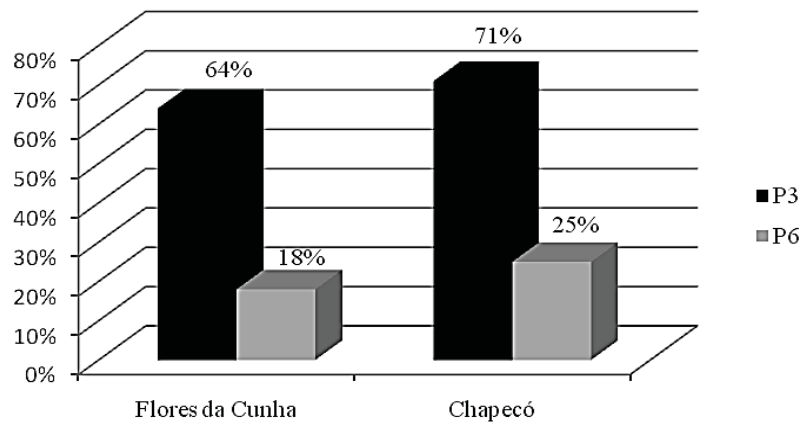

Fonte: Autor

Ainda que a pouca quantidade de dados de P6 seja responsável pela diferença na frequência de aplicação entre uma pesquisa e outra, o total de dados não enviesa o resultado comparativo entre P3 e P6, uma vez que em ambos os trabalhos é pequena a diferença de frequência entre uma cidade e outra, mantendo-se a cidade gaúcha como a mais preservadora de /e/ final.

Como mostra o Gráfico 7, os resultados de P3 e P6 não se diferenciam na mesma proporção que os de P6 e P8. No entanto, os resultados de frequência em P6 e P8 para a vogal /e/ em Curitiba também reflete a diferença na quantidade de dados: P8 analisa 1.970 contextos para a capital paranaense e constata uma taxa de $53 \%$ de aplicação da regra, ou seja, 1.056 casos de elevação; P6 analisa 100 ocorrências de /e/ átono final para essa cidade, das quais 37 foram produzidas com elevação.

Gráfico 7Resultado para Curitiba em P6 e P8: vogal/e/

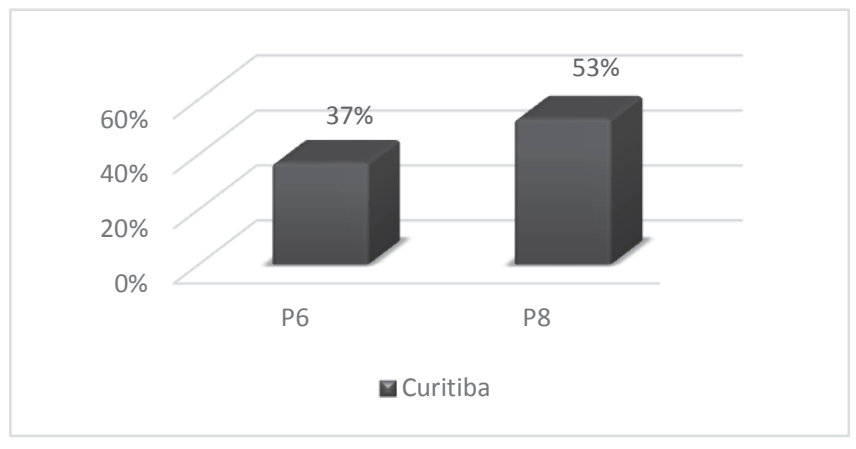

Fonte: Autor

Salientamos que, comparando-se o Gráfico 7, referente à frequência de aplicação de /e/ final em Curitiba, com os resultados do Gráfico 5, referente às cidades de Porto Alegre e Florianópolis, é possível notar que Curitiba figura como a capital mais preservadora de /e/ átono final. 
Seguindo-se com a análise das variáveis independentes de cada trabalho, observa-se que em P6 e P8 são controlados grupos de fatores distintos de acordo com a posição - final ou não final -, como mostra o Quadro 5, embora sejam as mesmas as variáveis controladas de acordo com cada posição. P3 controla Juntura e Classe de Palavra, não consideradas nos outros dois trabalhos.

Quadro 5 Variáveis linguísticas controladas em P3, P6 e P8

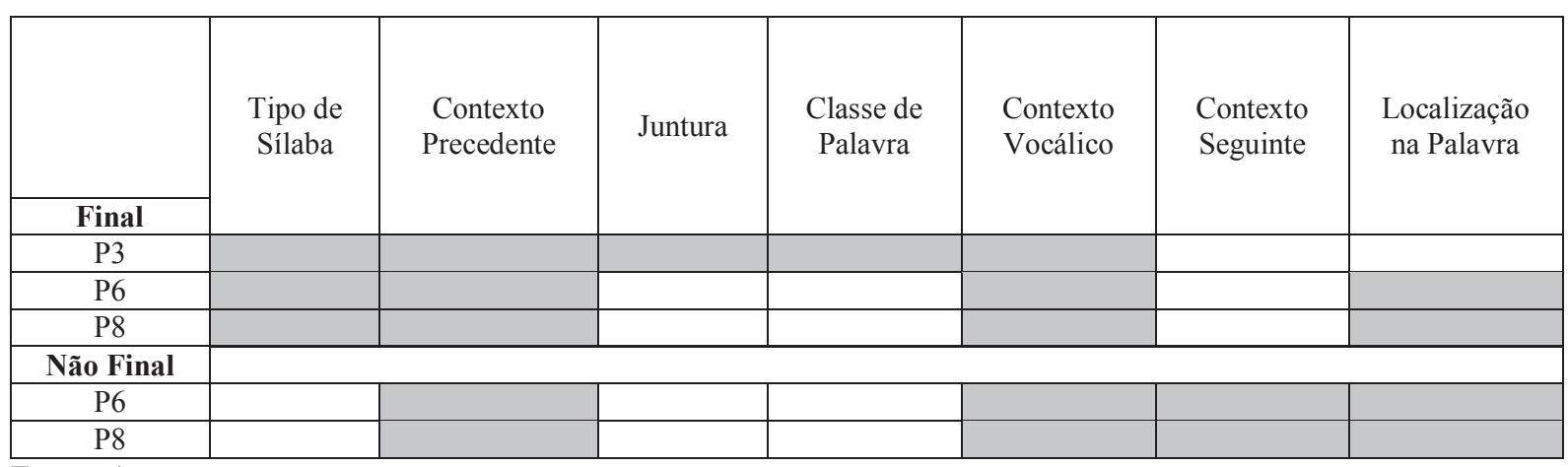

Fonte: Autor

Com relação às variáveis analisadas para a pauta átona final, Contexto Vocálico, Contexto Precedente e Tipo de Sílaba são comuns às três pesquisas. Para /o/ final, a variável Contexto Vocálico foi unanimemente selecionada, como se vê no Gráfico 8, embora em P3 os valores para peso relativo se aproximem do ponto neutro. Pelo resultado semelhante de P6 e P8, vê-se que a presença de vogal alta na palavra favorece a elevação de /o/ final.

Gráfico 8 Contexto Vocálico em P3, P6 e P8: vogal /o/

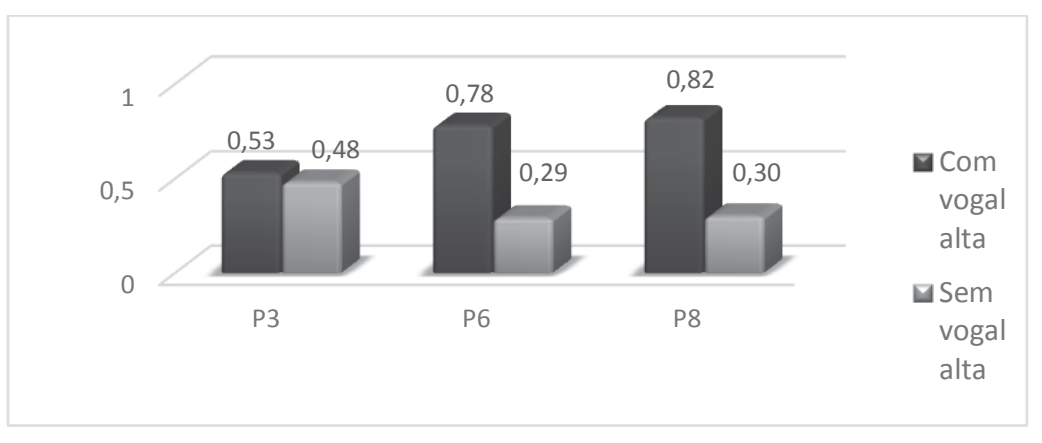

Fonte: Autor

Para a vogal /e/ em pauta átona final, Contexto Precedente e Tipo de Sílaba foram variáveis indicadas como relevantes em todos os trabalhos. Com relação aos resultados de Contexto Precedente, P3 mostrou dorsais e palatais como levemente favorecedoras $(0,57)$; vogais e consoantes labiais, dentais e alveolares mostraram comportamento neutro. Diferentemente, em P6 os segmentos /s, z/ mostraram-se claramente favorecedores da elevação $(0,70)$, seguidos das labiais $(0,62)$; coronais e dorsais foram pouco favorecedoras. Nota-se aqui a diferente composição da variável e, com isso, resultados discordantes: P3 trata coronais oclusivas e fricativas conjuntamente, o que as torna um fator neutro à aplicação da regra; P6 separa /s, z/ das demais coronais e os resultados mostram comportamento distinto. P8 indica as coronais oclusivas como inibidoras da elevação de /e/ $(0,40)$, e os demais segmentos como favorecedores $(0,75)$. O que se pode generalizar de tais resultados é o papel inibidor das coronais oclusivas para a elevação de /e/ final. 
Embora a composição da variável seja distinta em P3, P6 e P8, os resultados para Tipo de Ślaba são unânimes com relação ao papel favorecedor de coda /S/, como mostra o Gráfíco 9. P6 indica o favorecimento à elevação também em sílabas abertas, que em P3 e P8 mostram comportamento neutro. P3 indica ainda coda $/ \mathrm{N} /$ como favorecedora, no entanto, em P6 e P8 não é possível confirmar tal resultado, pois, amalgamada com coda $/ \mathrm{r} /$ e coda $/ 1 /$ sob a denominação coda soante, mostra-se bastante inibidora.

Gráfico 9 Tipo de Sílaba em P3, P6 e P8: vogal /e/

Fonte: Autor

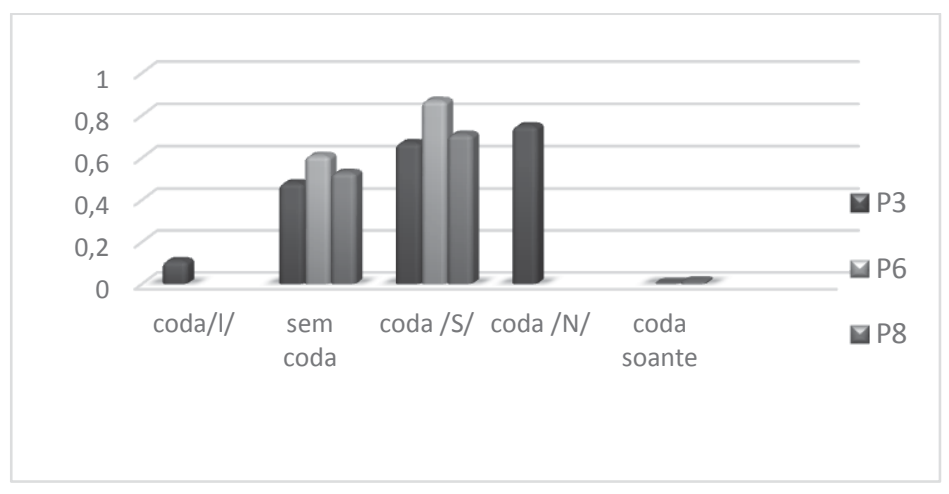

Das variáveis controladas na posição não final, Contexto Precedente foi indicado para ambas as vogais em P6 e P8, e seus resultados são generalizáveis. Para a elevação de /o/, consoantes labiais são favorecedoras tanto em P6 quanto em P8, como mostra o Gráfico 10; os demais segmentos apresentam comportamento pouco favorável à elevação.

Gráfico 10 Contexto Precedente em P6 e P8: /o/não final

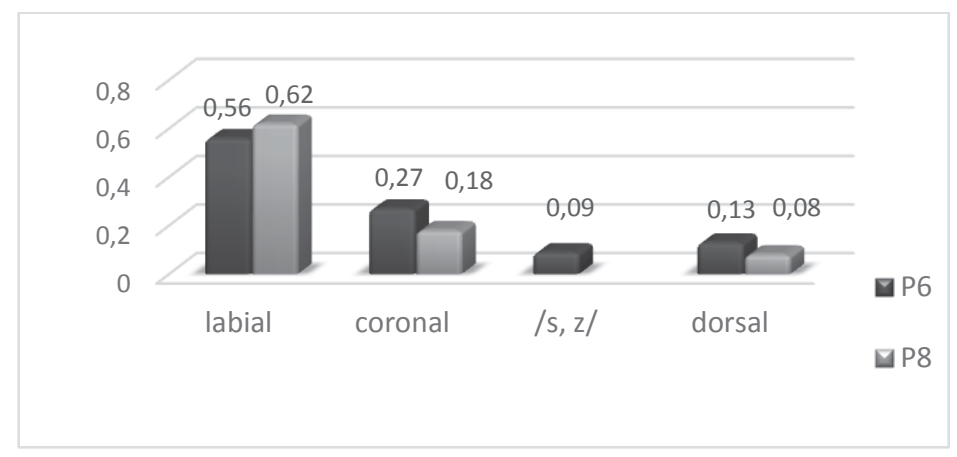

Fonte: Autor

Para a elevação de /e/ não final mostram-se favorecedoras também nas duas pesquisas as coronais fricativas. Labiais mostram comportamento próximo ao ponto neutro, e coronais não favorecem a aplicação da regra, como mostra o Gráfico 11. 
Gráfico 11 Contexto Precedente em P6 e P8: /e/ não final

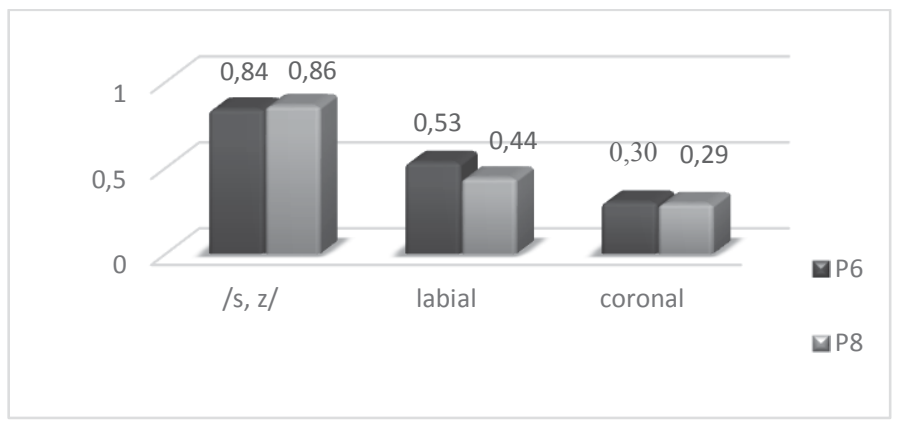

Fonte: Autor

Pela análise de P3, P6 e P8, é possível encontrar generalizações. Em posição final, presença de vogal alta alimenta a elevação de /o/ (Gráfico 8), e coda /S/ a elevação de /e/ (Gráfíco 9); nessa posição, coronais oclusivas em contexto precedente inibem a elevação da vogal média anterior. Em pauta átona não final, Contexto Precedente é a variável que condiciona a elevação das duas vogais - consoantes labiais favorecem a elevação de /o/ (Gráfico 10), e fricativas coronais, a de /e/ (Gráfico 11).

As outras quatro pesquisas - P4, P5, P7 e P9 (Quadro 6) - não são diretamente comparáveis considerando-se a origem dos dados. P4 (CARNIATO, 2000) analisa dados de 12 informantes residentes em Santa Vitória do Palmar - RS, cidade fronteiriça com o Uruguai, P5 (MALLMANN, 2001) descreve o fenômeno a partir de dados de 36 informantes de Santo Ângelo - RS, P7 (MACHRY DA SILVA, 2009) analisa a fala de 14 informantes da localidade de Rincão Vermelho, no município de Roque Gonzales - RS, fronteira com a Argentina, e P9 (MILESKI, 2013) analisa dados de 24 descendentes de imigrantes poloneses da cidade de Vista Alegre do Prata - RS. Os dados são oriundos de coletas pessoais realizadas pelos autores de cada estudo. Mostramos no Quadro 6 as características das amostras de P4, P5, P7 e P9.

Quadro 6 Características das amostras de P4, P5, P7 e P9

\begin{tabular}{|c|c|c|c|c|c|c|}
\hline $\begin{array}{l}\text { Autor/ } \\
\text { ano }\end{array}$ & Localidade & $\begin{array}{c}\text { Total de } \\
\text { informantes } \\
\text { e de dados }\end{array}$ & Faixa etária & Escolaridade & Sexo & $\begin{array}{l}\text { Grupo } \\
\text { étnico }\end{array}$ \\
\hline $\begin{array}{c}\text { P4 } \\
\text { Carniato } \\
(2000) \\
\end{array}$ & $\begin{array}{l}\text { Santa Vitória } \\
\text { do Palmar }\end{array}$ & $\begin{array}{l}12 \text { inf. } \\
\text { /o/ } 893 \\
\text { /e/ } 419 \\
\end{array}$ & $\begin{array}{l}\text { 13-18 anos } \\
+ \text { de } 50 \text { anos }\end{array}$ & $\begin{array}{c}1^{\circ} \mathrm{Grau} \\
\text { incompleto } \\
1^{\mathrm{o}} \text { Grau completo }\end{array}$ & - & - \\
\hline $\begin{array}{l}\text { P5 } \\
\text { Mallmann } \\
\text { (2001) }\end{array}$ & Santo Ângelo & $\begin{array}{l}36 \text { inf. } \\
\text { /e/ e /o/ em } \\
\text { conjunto } \\
2.891\end{array}$ & $\begin{array}{c}06-24 \text { anos } \\
25-49 \text { anos } \\
50 \text { anos ou } \\
\text { mais }\end{array}$ & $\begin{array}{l}\text { Fundamental } \\
\text { Médio-Superior }\end{array}$ & $\begin{array}{l}\text { masculino } \\
\text { feminino }\end{array}$ & $\begin{array}{c}\text { luso- } \\
\text { brasileiro } \\
\text { misto } \\
\text { alemão } \\
\text { italiano } \\
\text { polonês }\end{array}$ \\
\hline $\begin{array}{c}\text { P7 } \\
\text { Machry da } \\
\text { Silva } \\
\text { (2009) }\end{array}$ & $\begin{array}{l}\text { Rincão } \\
\text { Vermelho } \\
\text { (Roque } \\
\text { Gonzales) }\end{array}$ & $\begin{array}{l}14 \text { inf. } \\
\text { final: } \\
\text { /o/ } 5.951 \\
\text { /e/ } 3.883 \\
\text { não final: } \\
\text { /o/ } 223 \\
\text { /e/ } 310 \\
\end{array}$ & $\begin{array}{c}15-35 \text { anos } \\
36-57 \text { anos } \\
58 \text { anos ou } \\
\text { mais }\end{array}$ & $\begin{array}{l}\text { Fundamental } \\
\text { Médio } \\
\text { Superior }\end{array}$ & $\begin{array}{l}\text { masculino } \\
\text { feminino }\end{array}$ & 1 \\
\hline $\begin{array}{c}\text { P9 } \\
\text { Mileski } \\
(2013)\end{array}$ & $\begin{array}{l}\text { Vista Alegre } \\
\text { do Prata }\end{array}$ & $\begin{array}{l}24 \text { inf. } \\
\text { /o/ } 12.521 \\
\text { /e/ } 5.980\end{array}$ & $\begin{array}{c}15-35 \text { anos } \\
36-57 \text { anos } \\
58 \text { anos ou } \\
\text { mais } \\
\end{array}$ & $\begin{array}{l}\text { Fundamental } \\
\text { Médio } \\
\text { Superior }\end{array}$ & $\begin{array}{l}\text { masculino } \\
\text { feminino }\end{array}$ & polonês \\
\hline
\end{tabular}

Fonte: Autor 
Como se pode observar no Quadro 6, os trabalhos analisam dados de comunidades distintas, coletados em diferentes épocas - cada qual no período anterior à publicação da pesquisa - e utilizam estratégias diversas de constituição da amostra: P4 analisa apenas a posição final e separa as vogais; P5 atém-se também à posição final, mas trata /e/ e /o/ conjuntamente; P7 analisa separadamente as vogais e também as posições; e P9 analisa, assim como P4, apenas a posição final, tratando as vogais separadamente. A estratificação dos informantes por faixa etária é outro aspecto que distingue especialmente P4, P5 e P7: P4 trabalha com dados de adolescentes (13-18 anos) e adultos mais velhos (mais de 50 anos); P5 analisa dados de crianças a partir de 6 anos até adultos com mais de 50; e P7 estratifica, assim como P5, em três faixas etárias, no entanto, sua primeira faixa etária é composta por jovens e adultos (15-35 anos). $\mathrm{P} 9$ realiza estratificação idêntica à de $\mathrm{P} 7$.

A amostra das pesquisas distingue-se também com relação à variável escolaridade: os informantes de P4 têm $1^{\circ}$ Grau completo ou incompleto; os de P5 estão divididos em Ensino Fundamental e Médio-Superior; P7 e P9 separam entre Ensino Fundamental, Ensino Médio e Ensino Superior.

Analisadas tais distinções de origem dos dados e estratégias de análise adotadas, concluímos que P4, P5, P7 e P9 não são trabalhos diretamente comparáveis; restringimo-nos, portanto, a apontar desses estudos os resultados que confirmam as generalizações encontradas nos trabalhos analisados anteriormente.

A análise de P4, referente a dados de Santa Vitória do Palmar, não confirma nenhuma das generalizações encontradas. A variável apontada como mais significativa para a aplicação da regra foi Faixa Etária, verificando-se um processo de variação em progresso implementado pelos jovens. Ressalta-se, no entanto, que a composição da variável influencia o resultado, tendo em vista que os informantes representam duas gerações bem distintas: adolescentes versus adultos mais velhos.

Com relação aos resultados de $\mathrm{P} 5$, o favorecimento de /S/ pós-vocálico confirma a generalização encontrada referente à coda /S/ nos dados do VARSUL, em P3, P6 e P8. Ressalta-se, contudo, que nos dados das três pesquisas anteriores esse resultado foi comum apenas à vogal /e/, e em P5 reflete o comportamento das vogais médias em conjunto.

Os resultados de P7 para a vogal /e/ final confirmam a generalização em P1 e P2 referente ao favorecimento de velares e palatais em contexto precedente, tendo em vista que na pesquisa de Machry da Silva (2009) foram consoantes dorsais e os segmentos [s, z, J, 3] os que mais favoreceram a aplicação da regra.

P7 confirma também a generalização referente ao papel de coda /S/ para a elevação da vogal /e/ encontrada pela análise de P3, P6 e P8, como se pode ver no Gráfico 12. 
Gráfico12 Tipo de Sílaba em P3, P6, P7 e P8: /e/ final

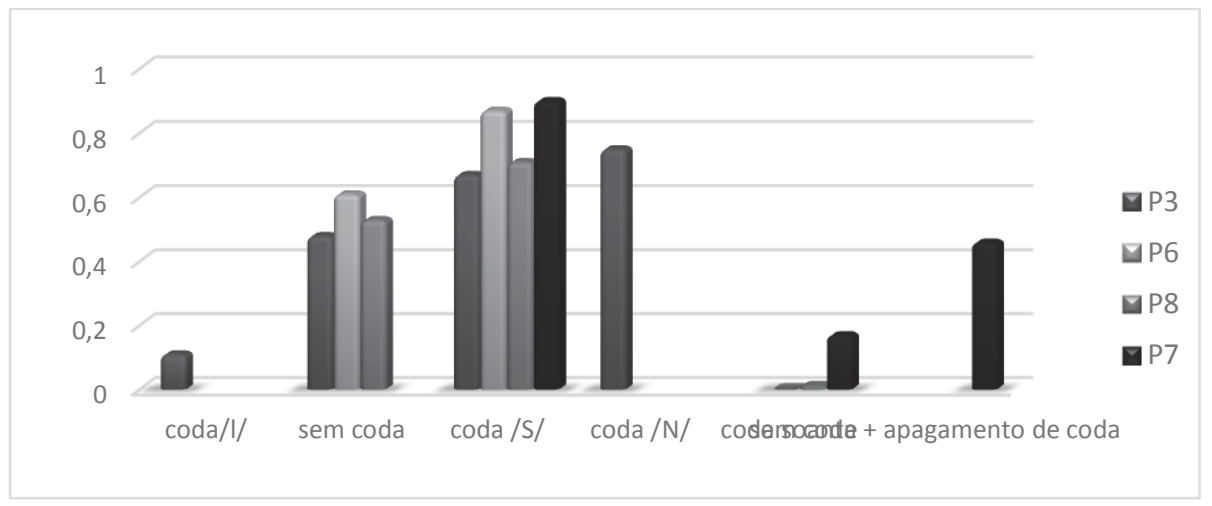

Fonte: Autor

Os resultados para /o/ final de P7 corroboram ainda a generalização referente ao papel da presença de vogal alta para a elevação de /o/, encontrada nas três pesquisas com dados do VARSUL, como se pode ver no Gráfico 13.

Gráfico 13 Resultados para Contexto Vocálico em P3, P6, P7 e P8: /o/ final

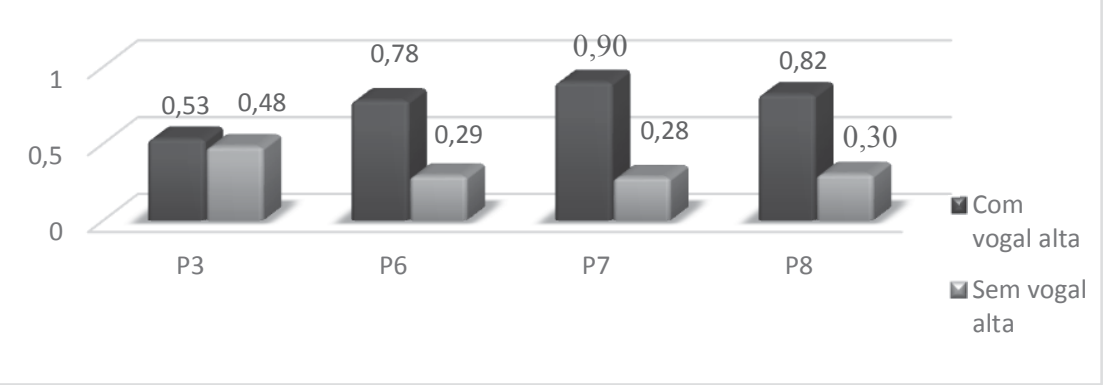

Fonte: Autor

Nota-se que P7 e P8 apresentam resultado de peso relativo bastante semelhante, e ocorre em P7 maior polarização em comparação às demais pesquisas.

No que se refere aos resultados de P7 para a posição não final, o papel favorecedor das labiais em contexto precedente a /o/ confirma o resultado comum entre P6 e P8. Como se pode ver no Gráfico 14, P7 é a pesquisa em que labiais em contexto precedente a /o/ apresentam maior peso relativo.

Gráfico 14 Contexto Precedente em P6, P7 e P8: /o/ não final

Fonte: Autor

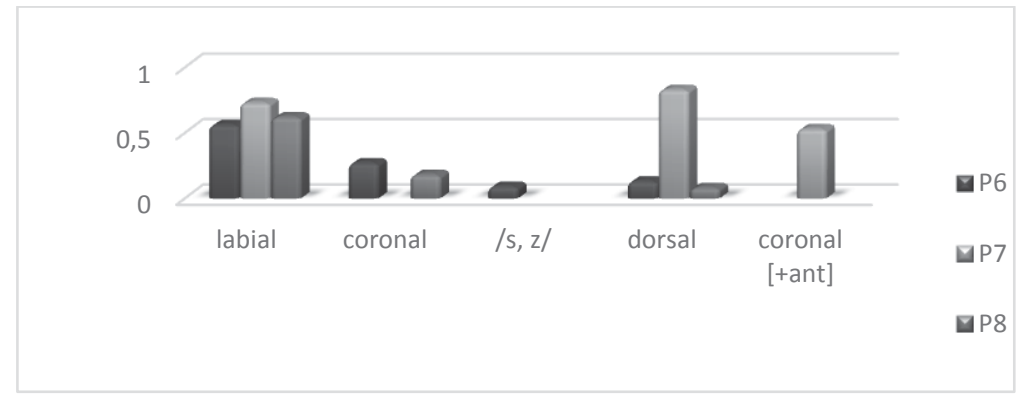

Os resultados de P9, referentes aos dados de Vista Alegre do Prata, também confirmam generalizações encontradas a partir de estudos anteriores. No que se refere à vogal/e/, o papel 
do contexto precedente confirma a generalização encontrada nos resultados de P1, P2 e P7, de que favorecem a elevação de /e/ postônico consoantes velares e palatais em contexto precedente. Como é possível ver no Gráfico 15, os valores de peso relativo ficam bastante acima do ponto neutro em todos os estudos. P7 e P9 apresentam a mesma denominação para o fator: dorsais, incluídas velares e palatais. Apenas para P2, como afirmado anteriormente, o resultados do fator mostra o comportamento conjunto de dorsais com outros segmentos.

Gráfico 15 Papel de Contexto Precedente em P1, P2, P7 e P9: vogal /e/

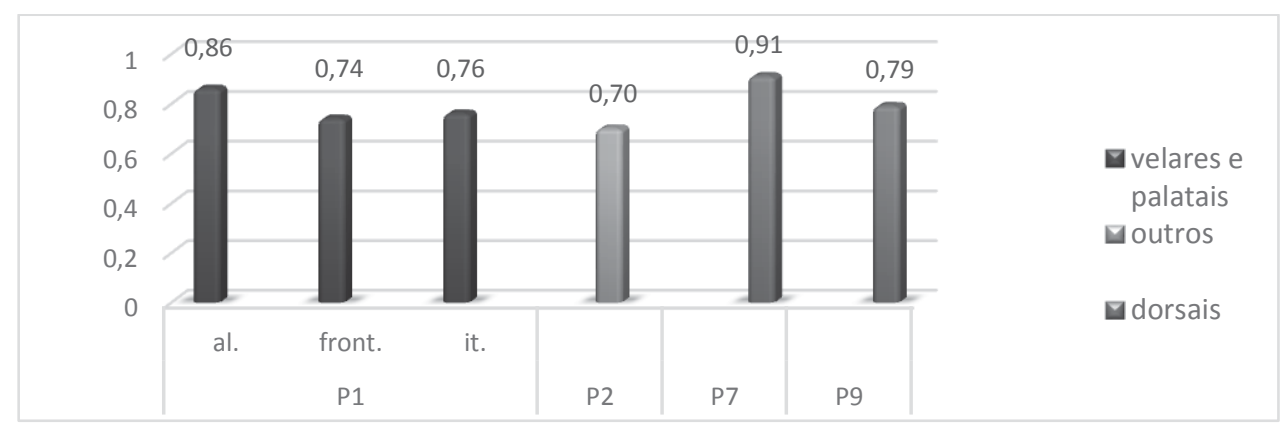

Fonte: Autor

Salientamos novamente a diferença de tratamento dos dados que se verifica entre essas quatro pesquisas: P1 e P2 tratam conjuntamente as posições, postônica final e não final, e em P7 e P9 esse resultado se refere apenas à posição final.

Como mostra o Gráfico 16, os resultados de P9 para a vogal /o/ átona final também confirmam a generalização referente ao papel da vogal alta em sílaba tônica para a elevação de $/ \mathrm{o} /$.

Gráfico 16 Contexto Vocálico da Sílaba Tônica em P3, P6 e P8, P7 e P9: /o/ átono final

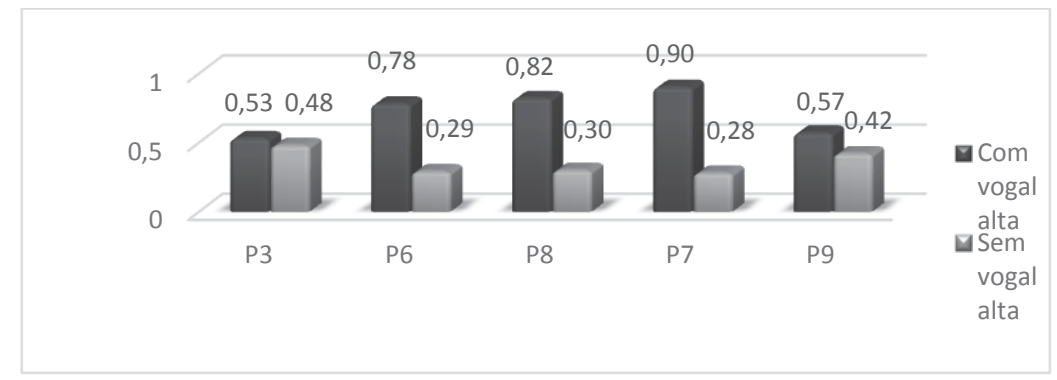

Fonte: Autor

Os resultados de P9 para a variável Contexto Vocálico da Sílaba Tônica não são polarizados, mas, embora exibam comportamento mais modesto de uma vogal alta na palavra, estão de acordo com a generalização encontrada nos dados do VARSUL e na amostra de Rincão Vermelho - RS.

\section{RESULTADOS GENERALIZÁVEIS ENCONTRADOS}

Com a análise dos nove estudos referentes à elevação das vogais médias postônicas no Sul do Brasil, foi possível chegar às seguintes generalizações:

a) favorecem a elevação de /e/ átono final:

- consoantes velares e palatais em contexto precedente (P1 e P2; P7; P9); 
- coda /S/ (P3, P6, P8; P7);

b) favorecem a elevação de /o/ átono final:

- presença de vogal alta, esteja ou não na sílaba tônica (P3, P6, P8; P7; P9);

c) favorecem a elevação da vogal /e/ não final:

- fricativas coronais em contexto precedente (P6 e P8);

d) favorecem o alçamento de /o/ não final:

- consoantes labiais em contexto precedente (P6 e P8; P7);

e) inibem a elevação de /e/ átono final:

- coronais oclusivas em contexto precedente (P3, P6 e P8);

f) atribui-se à influência da Variável Geográfica, no Rio Grande do Sul, a existência de dois sistemas vocálicos em pauta postônica: o de três vogais - /i, a, u/ -, e o que preserva as médias, com cinco vogais - /i, e, a, o, u/.

\section{CONSIDERAÇÕES FINAIS}

Este estudo teve por objetivo analisar nove pesquisas variacionistas sobre elevação das vogais médias postônicas no Sul do Brasil, no intuito de encontrar resultados generalizáveis. A análise desses estudos mostrou ser possível encontrar fatores linguísticos com comportamento regular na regra de elevação das vogais médias e, portanto, alcançar generalizações. Diferenças relacionadas especialmente à origem dos dados e à constituição da amostra, no entanto, impediram que se seguisse a metodologia de comparação adotada nos primeiros estudos aos últimos apresentados, uma vez que cada um deles descreveu diferentes comunidades de fala, com dados coletados em épocas distintas. Todavia, foi possível verificar que certas generalizações atingidas via estudos diretamente comparáveis neles foram constatadas.

Tendo em vista o significativo número de trabalhos variacionistas já disponíveis, acredita-se na relevância de estudos como este, cuja pretensão não foi maior do que encontrar resultados comuns entre pesquisas sobre elevação das vogais médias postônicas no Sul do Brasil.

\section{REFERÊNCIAS}

BAILEY, G; TILLERY, J.Some sources of divergent data in Sociolinguistics. In:FOUGHT, C. (ed.). Sociolinguistic Variation: Critical Reflections. New York: OxfordUniversity, 2004. p. 11-30.

BRESCANCINI, C. R. Sobre o efeito dos fatores estruturais na generalização de resultados: a elevação da vogal postônica em dados do Varsul. Fórum Linguístico. Florianópolis. n. 5, v. 1, p. 47-61, jan-jun, 2008.

CARNIATO, M. C. A neutralização das vogais postônicas finais na comunidade de Santa Vitória do Palmar. 2000. 107 f. Dissertação (Mestrado em Letras). Curso de Mestrado em Letras, Universidade Católica de Pelotas, Pelotas. 
MACHRY DA SILVA, S. Elevação das vogais médias átonas finais e não finais no português falado em Rincão Vermelho - RS. 2009. 172 f. Dissertação (Mestrado em Letras) Programa de Pós-Graduação em Letras, Pontifícia Universidade Católica do Rio Grande do Sul, Porto Alegre.

MALLMANN, D. O. A elevação das vogais médias átonas finais no português falado em Santo Ângelo (RS). 2001. 99 f. Dissertação (Mestrado em Letras) - Programa de PósGraduação em Letras, Pontifícia Universidade Católica do Rio Grande do Sul, Porto Alegre.

MILESKI, I. A elevação das vogais médias átonas finais no português falado por descendentes de imigrantes poloneses em Vista Alegre do Prata - RS. 2013. 152 f. Dissertação (Mestrado em Letras) - Programa de Pós-Graduação em Letras, Pontifícia Universidade Católica do Rio Grande do Sul, Porto Alegre.

ROVEDA, S. D. Elevação da vogal média átona final em comunidades bilingues: português e italiano. 1998. 87 f. Dissertação (Mestrado em Letras). Programa de Pós-Graduação em Letras, Pontifícia Universidade Católica do Rio Grande do Sul, Porto Alegre.

SCHMITT, C. J. Redução vocálica postônica e estrutura prosódica. 1987. 139 f. Dissertação (Mestrado em Letras) - Curso de Pós-Graduação em Letras, Universidade Federal do Rio Grande do Sul, Porto Alegre.

VIEIRA, M. J. B. Neutralização das vogais médias postônicas. 1994.110 f. Dissertação (Mestrado em Letras) - Curso de Pós-Graduação em Letras, Universidade Federal do Rio Grande do Sul, Porto Alegre.

As vogais médias postônicas: uma análise variacionista. In: BISOL, L.; BRESCANCINI, C. (org.). Fonologia e variação: recortes do português brasileiro. Porto Alegre: EDIPUCRS, 2002, p 127- 159.

. As vogais médias átonas no sul do Brasil. In: MARÇALO M. J.et al. (Ed.). Língua portuguesa: ultrapassar fronteiras, juntar culturas. Évora: Universidade de Évora, 2010.

Disponível em: <http://www.simelp2009.uevora.pt/pdf/slg5/01.pdf>. Acesso em: 26 nov. 2011. 